\title{
Evidence on nutritional therapy practice guidelines and implementation in adult critically ill patients: A systematic scoping review
}

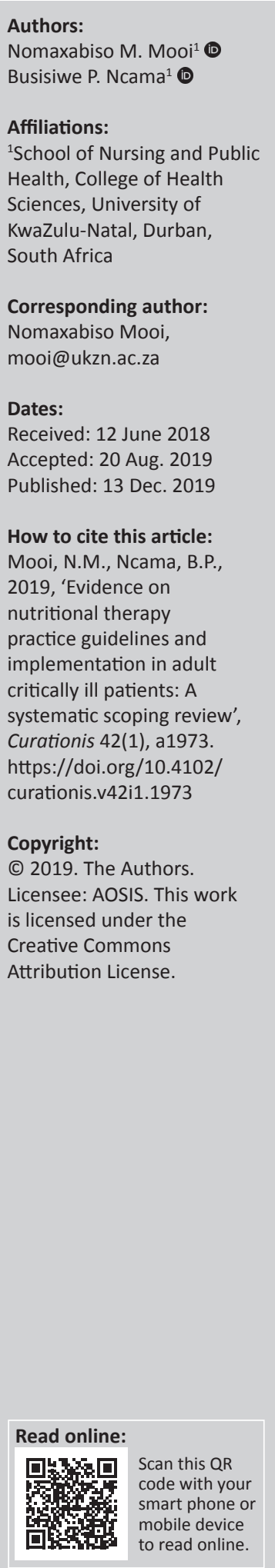

Background: The rapid increase in disease-related malnutrition makes it almost impossible for healthcare practitioners and policymakers to keep up with its negative consequences. Consequently, healthcare organisations and decision-makers have called for accelerated and double-duty actions to manage the double burden of malnutrition. Guidelines standardise nutritional practices, improve nutritional status and reduce hospitalisation duration and save costs.

Objectives: A systematic scoping review of the nutritional therapy practice guidelines and implementation in critically ill adults was undertaken to identify the breadth of literature on the topic, summarise findings and identify gaps.

Methods: A comprehensive search strategy was designed and implemented to identify eligible studies from eight databases, websites of organisations, government departments and academic platforms. Reference lists of included studies were also searched for relevant studies. We assessed the quality of included studies, completed a descriptive numerical summary and analysed them.

Results: In total, 1555 titles and 101 abstracts were screened, 65 underwent full text review and 19 were retained for data extraction. Studies scored average to high on quality assessment, and a summary of characteristics of included studies is presented. Nutritional therapy practice guidelines are considered a proactive strategy for enhanced, uniform and individualised nutritional practices and factors that influence implementation were identified.

Conclusions: A gap exists between research recommendations and actual practice despite the growing interest in implementation of nutritional therapy guidelines in critical care. There is a need for more research to evaluate the practicality of available guidelines.

Keywords: critically ill adults; nutritional therapy; practice guidelines; implementation; enteral nutritional therapy protocol; parenteral nutritional therapy protocol; algorithm; scoping review.

\section{Background}

The quadruple burden of communicable and non-communicable diseases, perinatal and maternal conditions, and injury-related disorders has resulted in a double burden of malnutrition, which is defined as the combination of over- and undernutrition (Mayosi \& Benatar 2014:1345; WHO 2017:1). People live longer because of modern treatment of these diseases, and many are either chronically underweight or overweight and therefore are vulnerable to acute illness (National Collaborating Centre for Acute Care 2006:2; WHO 2017:1). This poses a real and growing global health challenge that warrants urgent nutrition actions, and puts pressure on acute care services, which include critical care (Hirshon et al. 2013:386; WHO 2016, 2017:6).

Malnutrition is very common in acutely ill patients, occurring in 30\% - 50\% of hospitalised patients and the number may be higher in critically ill patients, and is associated with increased complication risk, high healthcare costs and increased long-term mortality (Jones et al. 2008:301; Wischmeyer 2013:2). This is attributed to critically ill patients having decreased volitional nutrition intake and therefore being completely dependent on their care providers for their nutritional needs. The phrase 'critically ill' refers to patients $\geq 18$ years of age, with a high severity of disease score, with one or more organ dysfunctions and needing a single or multiple invasive therapeutic intervention(s) (Boniatti et al. 2011). These patients always receive poor nutrition for a prolonged period as nutritional therapy is often only an afterthought on care rounds in most severely ill patients (Wischmeyer 2013:2). 
Optimal nutritional therapy has become an important component in the management of critical illness. It is relatively inexpensive compared to other commonly used treatments and is a determinant of quality in patient care (Bousie et al. 2016:e47; Padilla Fuentes et al. 2016:1219; Ridley, Gantner \& Pellegrino 2015:565; Warren, McCarthy \& Roberts 2016:334). However, despite its important benefits, nutritional practices in critically ill patients remain widely varied, leading to inappropriate and suboptimal nutrition delivery with harmful consequences (Ridley et al. 2015:365). As a result, critically ill patients receive only about $50 \%$ of prescribed nutrition in the first 2 weeks following intensive care unit (ICU) admission (Peev et al. 2015:21). Many studies recommend the development and implementation of nutritional therapy guidelines to assist and improve nutritional practices (Bousie et al. 2016:e47; Keller et al. 2015:1; Kim et al. 2017:27). In this study, nutritional therapy is referred to as nutritional support, which will be either enteral nutrition (EN) or parenteral nutrition (PN). Various operational versions of guidelines adapted to local requirements and easy application in clinical practice such as protocols, algorithms and clinical practice guidelines (CPGs) are used to enhance international guidelines implementation (Friesecke et al. 2014:204; Kiss et al. 2012; Mesejo et al. 2011:2).

Guidelines are developed to assist practitioner and patient decisions about appropriate healthcare for specific clinical circumstances, are designed to minimise variation, improve costs and improve outcomes (Dhaliwal et al. 2014:29). They offer basic recommendations supported by review and analysis of the current literature, other national and international guidelines and a blend of expert opinion and clinical practicality (McClave et al. 2016:159; Taylor et al. 2016:391). Additionally, the important aspect of any guidelines is their transparency, that is, the methodical review which links the recommendation to the supporting evidence is clearly stated (Martindale, McCarthy \& McClave 2011:463). They should be interpreted and used through the scope of individual institutional practices, and should be based on individual preferences, patient mix, and local expertise. Thus, an effective guideline is clinically practical (Martindale et al. 2011:463). The aim of this review was to map the literature on the availability and implementation of nutritional therapy guidelines in critically ill adults. It is expected that the results of this study may help identify gaps and indications for future researches on the topic.

\section{Methodology}

We followed Arksey and O'Malley's scoping review methodological framework, adapted by Levac, Colquhoun and O'Brien (Arksey \& O'Malley 2005; Levac et al. 2010), with the following stages.

Stage 1: Identifying the research question

Stage 2: Identifying relevant studies

Stage 3: Study selection
Stage 4: Charting the data

Stage 5: Collating, summarising and reporting the results Stage 6: Consultation (optional).

\section{Identifying the research question}

The main objective of this scoping review was to map the literature on the extent and implementation of nutritional therapy guidelines among critically ill adults, describe key findings and identify emerging themes. Therefore, the broad question the review asked was, 'what evidence exists on nutrition therapy guidelines and implementation in adult critically ill patients?'

\section{Determining the eligibility of the review question}

To determine the eligibility of the research question, the Population, Concept, Context (PCC) framework was followed as shown in Table 1.

\section{Identifying relevant studies and grey literature}

The purpose of the study guided the scoping review to identify published and unpublished studies and reviews suitable for answering the central research question. A comprehensive search was conducted in PubMed, Google Scholar, EBSCO databases, namely Cumulative Index for Nursing and Allied Health Literature (CINAHL), Medline Psych INFO, Psych ARTICLES, Health Source-Consumer Edition and Health Source: Nursing/Academic Edition. Relevant organisations such as the World Health Organization international and academic sources from Open Access for Theses and Dissertations provided grey literature. Keywords and MeSH terms were used to search for studies, guided by the predetermined PCC format and research question. These were separated or combined into phrases by Boolean terms such as 'OR' and 'AND' and included ICU OR critically ill adults, nutrition therapy OR nutritional support AND guidelines. The initial search strategy that was piloted on the PubMed database, which was adapted and used for other databases (see Table 2), includes the following:

TABLE 1: Eligibility criteria for the review question. A PCC framework for determination of eligibility of review question.

\begin{tabular}{ll}
\hline Variable & Description \\
\hline Population & $\begin{array}{l}\text { This study includes researches reporting on adult critically ill } \\
\text { patients, critically ill individuals of } \leq 18 \text { years of age, intensive care } \\
\text { unit (ICU) patients and critically ill persons. } \\
\text { Critically ill neonates, children and individuals below } 18 \text { years of age } \\
\text { were excluded. }\end{array}$ \\
& $\begin{array}{l}\text { This review included studies reporting on nutritional therapy } \\
\text { guidelines, nutritional policy for enteral and parenteral nutrition, } \\
\text { nutritional support guidelines, nutrition clinical practice } \\
\text { guidelines, enteral nutrition practice guidelines, parenteral } \\
\text { nutrition practice guidelines, artificial feeding guidelines, } \\
\text { nutritional practice recommendations, standardised nutritional } \\
\text { practices, nutritional therapy protocols, guides, procedures } \\
\text { and algorithms. } \\
\text { Studies reporting on oral or normal diet were not included. }\end{array}$ \\
& $\begin{array}{l}\text { The scoping review considered studies that discussed the } \\
\text { implementation of, compliance with or adherence to enteral or } \\
\text { parenteral nutritional therapy guidelines in the management of } \\
\text { critically ill patients. Studies from any geographic setting will be } \\
\text { eligible for inclusion. } \\
\text { Evidence not focusing on or including nutrition therapy guidelines } \\
\text { implementation, or effectiveness were excluded. }\end{array}$ \\
\hline PCC, Population, concept, context.
\end{tabular}

PCC, Population, concept, context. 
TABLE 2: Search terms per database.

\begin{tabular}{|c|c|c|c|c|}
\hline Search date & Database & Keywords/link & Articles retrieved & Eligible titles \\
\hline February 19, 2018 & PubMed & $\begin{array}{l}\text { Critically ill adults AND nutritional therapy guidelines: (('ICU') OR } \\
\text { ('critical illness' OR ('critical'[All Fields] AND 'illness'[All Fields]) OR } \\
\text { 'critical illness'[All Fields] OR ('critically'[All Fields] AND 'ill'[All Fields]) } \\
\text { OR 'critically ill'[All Fields]) AND ('adult'[MeSH Terms] OR 'adult'[All } \\
\text { Fields] OR 'adults'[All Fields])) AND (('nutritional support'[MeSH Terms] } \\
\text { OR ('nutritional'[All Fields] AND 'support'[All Fields]) OR 'nutritional } \\
\text { support'[All Fields] OR ('nutrition'[All Fields] AND 'therapy'[All Fields]) } \\
\text { OR 'nutrition therapy'[All Fields] OR 'nutrition therapy'[MeSH Terms] } \\
\text { OR ('nutrition'[All Fields] AND 'therapy'[All Fields])) AND } \\
\text { ('guideline'[Publication Type] OR 'guidelines as topic'[MeSH Terms] } \\
\text { OR 'guidelines'[All Fields]) }\end{array}$ & 224 & 39 \\
\hline February 19, 2018 & Google Scholar & $\begin{array}{l}\text { ICU OR critically ill OR critical illness AND adults, nutrition OR feeding OR } \\
\text { food, nutritional support OR nutritional therapy AND guidelines OR } \\
\text { protocols OR algorithms OR evidence-based recommendations OR } \\
\text { standard practice OR standardised practices }\end{array}$ & 764 & 25 \\
\hline February 19, 2018 & $\begin{array}{l}\text { EBSCO host databases: } \\
\text { MEDLINE with Full Text } \\
\text { CINAHL } \\
\text { Health Source: Nursing/Academic Edition } \\
\text { PsychINFO } \\
\text { Health Source-Consumer Edition } \\
\text { PsychARTICLES }\end{array}$ & $\begin{array}{l}\text { (ICU patients OR critically ill patients OR critical illness AND adults } \\
\text { OR adult patients) AND (nutrition OR feeding OR food, enteral nutrition, } \\
\text { parenteral nutrition, nutritional support OR nutritional therapy AND } \\
\text { guidelines OR protocols OR algorithms OR evidence-based } \\
\text { recommendations OR standard practice OR standardised practices) } \\
\text { (nutrition OR feeding OR food, enteral nutrition, parenteral nutrition, } \\
\text { nutritional support OR nutritional therapy guidelines OR protocols OR } \\
\text { algorithms OR evidence-based recommendations OR standard } \\
\text { practice OR standardised practices) }\end{array}$ & 541 & 66 \\
\hline February 21, 2018 & $\begin{array}{l}\text { Grey Literature: } \\
\text { WHO International sources; } \\
\text { Governmental websites; } \\
\text { Open Access for Theses and Dissertations }\end{array}$ & $\begin{array}{l}\text { Intensive care unit OR critically ill adults nutrition therapy AND } \\
\text { guidelines }\end{array}$ & 26 & 24 \\
\hline Total & & & 1555 & 154 \\
\hline
\end{tabular}

ICU, intensive care unit.

('ICU') OR ('critical illness' OR ('critical'[All Fields AND 'illness'[All Fields]) OR 'critical illness'[All Fields] OR ('critically'[All Fields] AND 'ill'[All Fields]) OR 'critically ill'[All Fields]) AND ('adult'[MeSH Terms] OR 'adult'[All Fields] OR 'adults'[All Fields])) AND (('nutritional support'[MeSH Terms] OR ('nutritional'[All Fields] AND 'support'[All Fields]) OR 'nutritional support'[All Fields] OR ('nutrition'[All Fields] AND 'therapy'[All Fields]) OR 'nutrition therapy'[All Fields] OR 'nutrition therapy'[MeSH Terms] OR ('nutrition'[All Fields] AND 'therapy'[All Fields]) AND ('guideline'[Publication Type] OR 'guidelines as topic'[MeSH Terms] OR 'guidelines'[All Fields]).

\section{Selection criteria}

\section{Inclusion criteria}

Studies were included if they were published between January 2002 and February 2018 and discussed critically ill or ICU adults. The start date of 2002 was chosen because many nutritional therapy practice guidelines were published around that period. Studies reporting on nutritional therapy, nutritional support, enteral and parenteral nutrition were included. Guidelines included any document designed to guide nutritional therapy practices or facilitate implementation of guidelines,namely, protocols,evidence-based recommendations, algorithms, nutrition standard practices and reference documents. All study designs such as qualitative, quantitative and mixed methods studies were deemed eligible.

\section{Exclusion criteria}

For the purpose of this review, we excluded studies reporting on critically ill adults on normal diet and critically ill patients younger than 18 years of age. Evidences from nutritional therapy guidelines in other groups other than critically ill adults were also excluded. Nutritional practice guidelines not focusing on enteral or parenteral nutritional therapy were not included. Conference abstracts, conference presentations, letters to editors and others, such as commentaries, editorials and studies published outside the preferred date range, were not included.

\section{Study selection}

The process involved three phases, namely title, abstract and full-text article screening using forms that were developed before the screening commenced. The first phase involved title screening, exporting them onto an EndNote library and removal of duplicates. Abstracts were obtained for included titles, and those articles for which abstracts were not available were included for abstract screening if the title was enough to indicate that nutritional therapy guidelines and implementation were discussed. Two independent reviewers screened abstracts and full text articles. For all articles that we considered relevant after title and abstract screening, we obtained full text articles and included them for data extraction. We resolved our disagreements by discussion, and a third reviewer was invited when necessary. SPSS version 25 was used to calculate Kappa's statistic to estimate the degree of agreement between reviewers. Reference lists of included studies were also searched to ensure that we considered all possible relevant articles. The results of study selection are shown in shown in Figure 1, adopted and adapted by the researcher (Liberati et al. 2009:4; Moher, Liberati \& Tetzlaff 2009:3).

\section{Data extraction}

A pretested data extraction form as described by Noyes and Lewin (2011) was used to extract data from included studies. The form was piloted on the first five studies to ascertain that it was in line with the research question. We extracted data relevant to nutritional therapy practice guidelines implementation by author, year of publication, country of origin, study aim, study setting, relevant results, significant results and authors' conclusions. Table 3 shows a summary of included studies. 


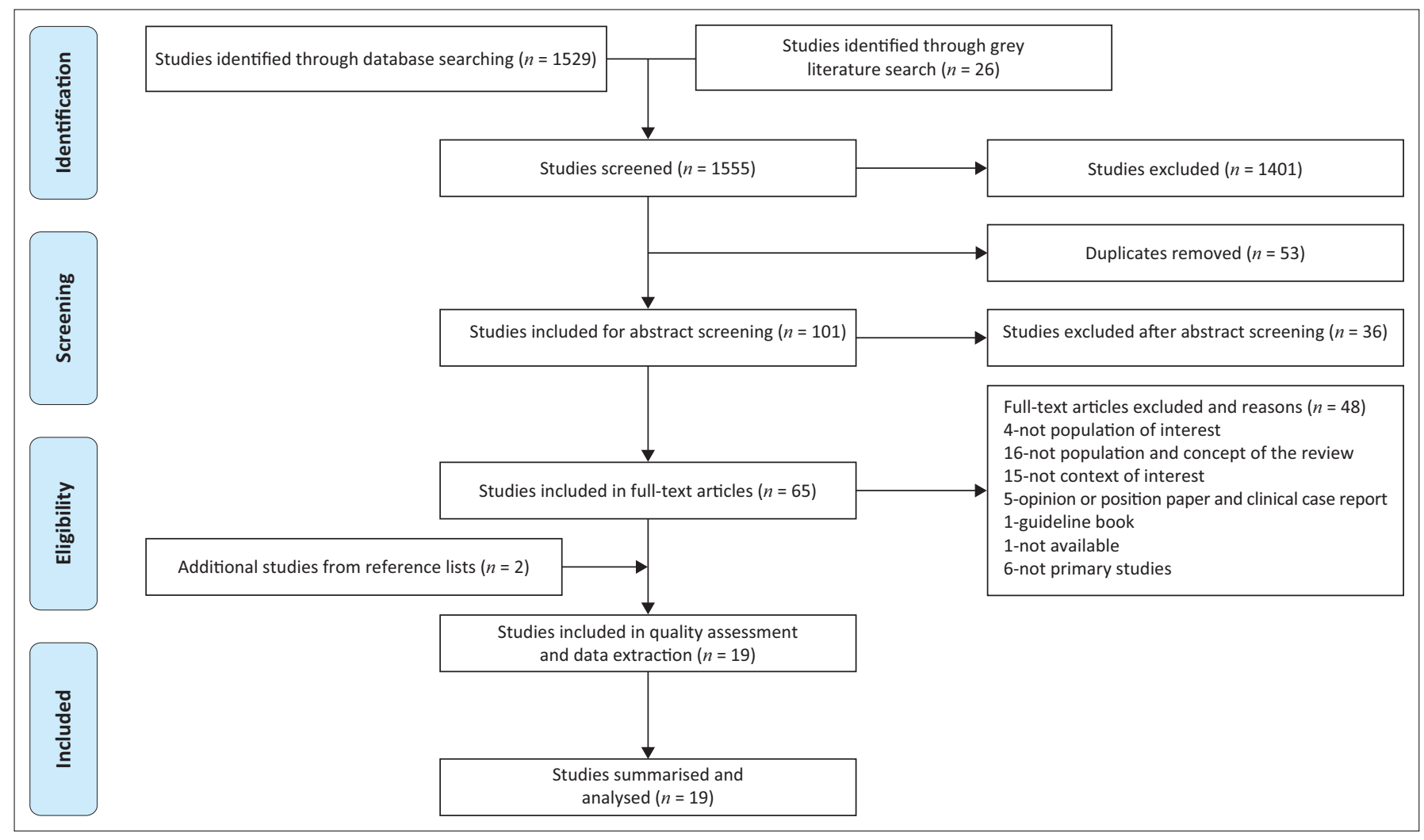

Source: Moher, D., Liberati, A. \& Tetzlaff, J., 2009, 'Preferred reporting items for systematic reviews and meta-analyses: The PRISMA statement', PLoS Medicine 6(7), 1-6. https://doi.org/10.1371/ journal.pmed.1000097

FIGURE 1: PRISMA flow diagram showing literature search and selection of studies.

TABLE 3: Summary of included studies.

\begin{tabular}{|c|c|c|}
\hline Characteristic & Number $(n=19)$ & $\%$ \\
\hline \multicolumn{3}{|l|}{ Publication year } \\
\hline 2004-2008 & 5 & 26 \\
\hline 2009-2012 & 4 & 21 \\
\hline 2013-February 2018 & 10 & 53 \\
\hline \multicolumn{3}{|l|}{ Guideline terminology } \\
\hline Clinical practice guideline (CPG) & 6 & 32 \\
\hline Protocol & 9 & 47 \\
\hline Algorithm & 4 & 21 \\
\hline \multicolumn{3}{|l|}{ Setting } \\
\hline Tertiary hospital ICU & 11 & 58 \\
\hline University or teaching hospital & 9 & 47 \\
\hline General hospital & 1 & 5 \\
\hline National Department of Health & 3 & 16 \\
\hline Not specified & 4 & 21 \\
\hline \multicolumn{3}{|l|}{ Aim or focus of the study } \\
\hline Effects of guideline implementation & 13 & 68 \\
\hline Rate of guideline implementation and other & 6 & 32 \\
\hline \multicolumn{3}{|l|}{ Study design } \\
\hline Retrospective & 7 & 37 \\
\hline Prospective & 9 & 47 \\
\hline Not specified & 3 & 16 \\
\hline \multicolumn{3}{|l|}{ Guideline type } \\
\hline Enteral Nutritional therapy (EN) & 6 & 32 \\
\hline Parenteral Nutritional therapy (PN) & 1 & 5 \\
\hline EN and PN & 12 & 63 \\
\hline
\end{tabular}

ICU, intensive care unit.

\section{Quality assessment}

Reviewers met to choose quality appraisal tools for included studies from both published (black) and unpublished (grey) literature. The Mixed Method Appraisal Tool (MMAT) version 2011 was employed to assess methodological quality of included primary studies (Pluye et al. 2011). The tool is designed to assess studies according to study design types or domains, namely all study types, quantitative randomised controlled and quantitative non-randomised and quantitative descriptive (Pace et al. 2012:47). No studies used qualitative, quantitative, descriptive or mixed methods, and no studies were excluded because of low quality. The scoring merits ranged between $25 \%$ and $100 \%$. A score of $25 \%-50 \%$ was rated as low quality, $51 \%-75 \%$ as average and $76 \%-100 \%$ as high quality.

A different tool, the authority, accuracy, coverage, objectivity, date and significance (AACODS) checklist was used to evaluate and critically appraise grey literature. The checklist comprises 28 items that are unevenly distributed under six domains. The tool did not come with scores, and scoring metrics were developed by the reviewers. In order to provide a quantitative estimate of the overall quality score, each item was allocated 3.6 points, which gave a total of 100 when multiplied by 28 (number of items). The overall quality score was set at 10 and the score index was $0.1-1$; a study with a score of four (40 points) or less was rated as weak, a study scoring between five and seven was rated moderate, while a score of eight and higher was considered strong. The summary of the quality assessment report of grey literature studies is shown in Table 4. 
TABLE 4: Summary of quality assessment report of included studies from databases (MMAT 2011).

\begin{tabular}{|c|c|c|c|c|c|c|c|}
\hline \multirow[t]{2}{*}{ Author and date } & \multirow{2}{*}{$\begin{array}{l}\text { Are there clear } \\
\text { qualitative and } \\
\text { quantitative or mixed } \\
\text { methods research } \\
\text { questions (or } \\
\text { objectives)? }\end{array}$} & \multirow{2}{*}{$\begin{array}{l}\text { Do the collected data } \\
\text { address the research } \\
\text { question (objective)? }\end{array}$} & \multicolumn{4}{|c|}{ Quantitative non-randomised controlled trials } & \multirow[t]{2}{*}{ Score $\%$} \\
\hline & & & $\begin{array}{l}\text { Are participants } \\
\text { recruited in a way } \\
\text { that minimises } \\
\text { selection bias? }\end{array}$ & $\begin{array}{l}\text { Are measurements } \\
\text { appropriate regarding } \\
\text { exposure/intervention } \\
\text { and outcomes? }\end{array}$ & $\begin{array}{l}\text { Are participants } \\
\text { comparable or difference } \\
\text { between these groups } \\
\text { taken into account? }\end{array}$ & $\begin{array}{c}\text { Are there } \\
\text { complete outcome } \\
\text { data ( } 80 \% \text { or } \\
\text { above) }\end{array}$ & \\
\hline Barr et al. 2004 & Yes & Yes & Yes & Yes & Yes & Yes & 100 \\
\hline Bousie et al. 2016 & Yes & Yes & Yes & Yes & Yes & Yes & 100 \\
\hline Cahill et al. 2010a & Yes & Yes & Yes & Yes & Yes & Yes & 100 \\
\hline Dervan et al. 2012 & Yes & Yes & Yes & Yes & Yes & Yes & 100 \\
\hline Dobson and Scott 2007 & Yes & Yes & Yes & Yes & No & Yes & 75 \\
\hline Heyland et al. 2004 & Yes & Yes & Yes & Yes & No & Yes & 75 \\
\hline Heyland et al. 2015 & Yes & Yes & Yes & Yes & Yes & Yes & 100 \\
\hline Kim et al. 2017 & Yes & Yes & Yes & Yes & Yes & Yes & 100 \\
\hline Kiss et al. 2012 & Yes & Yes & Yes & Yes & Yes & Yes & 100 \\
\hline Mackenzie et al. 2005 & Yes & Yes & Yes & Yes & Yes & Yes & 100 \\
\hline Quenot et al. 2010 & Yes & Yes & Yes & Yes & Yes & No & 75 \\
\hline Sungur et al. 2015 & Yes & Yes & Yes & Yes & Yes & Yes & 100 \\
\hline Wang et al. 2017 & Yes & Yes & Yes & Yes & Yes & Yes & 100 \\
\hline Wøien and Bjørk 2006 & Yes & Yes & Yes & Yes & Yes & Yes & 100 \\
\hline
\end{tabular}

\section{Collating, summarising and reporting results}

The goal of this scoping review is to analyse eligible studies to obtain an overview of the scientific literature on availability and implementation of nutritional therapy guidelines in critically ill adults. With this goal in mind, we summarised and presented the collection of key findings on the subject matter from eligible studies. Responses to these questions were collated, summarised and reported as results of our scoping review. Results of our study include both a descriptive numerical summary of the characteristics of included studies and a thematic analysis, based on the questions we asked during the charting process. Thematic analysis as described by Braun and Clarke (2006) was used to analyse qualitative data from the results sections of included studies. Results were collated, summarised and coded. The code list generated across the data sets was collated, sorted and searched for potential themes. Identified themes were then reviewed in search for final themes, which were then defined and named. Table 5 shows the themes that were generated.

\section{Ethical considerations}

The study is a review of literature and does not involve human participants.

\section{Results}

Eight databases were searched along with World Health Organization (WHO) International and Open Access for Theses and Dissertations (grey literature) and 1555 articles were identified. Following screening, 19 studies met the inclusion criteria (Figure 1). The degree of agreement between the reviewers was $80.0 \%$, while the Kappa statistics was 0.58 , $p<0.001$, which showed moderate to substantial level of agreement. McNemar's chi-square statistics suggests that there is no statistical significant difference in the proportion of 'yes' or 'no' reported by the screeners. Forty-eight studies were excluded at full text article screening stage with reasons. Thirty-five of these studies failed to meet the inclusion criteria; five were opinion papers or editorial letters, six of them were secondary studies, and two were excluded because one was a guideline booklet and one was not available.

\section{Characteristics of included studies}

A summary of descriptive characteristics of included studies is provided in Table 6. The studies were published between 2004 and 2017, with the majority appearing in the year preceding the scoping review, 2017 (Figure 2). Studies originated from 13 countries: four are from the USA (Barr et al. 2004; Compton et al. 2014; Dervan et al. 2012; Heyland et al. 2004); three from Canada (Cahill et al. 2014; Heyland et al. 2015; Mackenzie et al. 2005); South Africa (Africa 2016; National Department of Health 2017) and Brazil (Pasinato et al. 2013) published two studies each; and the remaining eight studies are from researchers located in Europe (Bousie et al. 2016), Pakistan (Sungur, Sahin \& Tasci 2015), United Kingdom (Dobson \& Scott 2007), Taiwan (Wang et al. 2017), Norway (Wøien \& Bjørk 2006), Ireland (Rice Niamh 2013), England (Quenot et al. 2010), Switzerland (Kiss et al. 2012) and Asia (Kim et al. 2012). Fourteen primary studies followed the prospective (Barr et al. 2004; Cahill et al. 2010b; Dobson \& Scott 2007; Heyland et al. 2004; Pasinato et al. 2013; Quenot et al. 2010; Windle 2009; Wøien \& Bjørk 2006) and retrospective research designs (Bousie et al. 2016; Compton et al. 2014; Kim et al. 2017; Kiss et al. 2012; Mackenzie et al. 2005; Wang et al. 2017), eight and six, respectively, two were multicentre quality improvement initiatives (Heyland et al. 2015; Quenot et al. 2010) and one was a quasi-experimental study (Sungur et al. 2015). With regard to studies from grey literature, two of them (National Department of Health 2016; National Department of Health 2017) were guideline documents based on literature review and expert opinion from South Africa, and one was a 
TABLE 5a: Summary of quality assessment report of included studies from grey literature (AACODS).

\begin{tabular}{|c|c|c|c|c|}
\hline Criteria & Description & IrSPEN Special Report No. 1, 2013 & National DoH, EN, 2016 & National DoH, PN, 2017 \\
\hline \multirow[t]{4}{*}{ Authority } & Is the organisation reputable? & 1 & 1 & 1 \\
\hline & Is the organisation an authority in the field? & 1 & 1 & 1 \\
\hline & Does the item have a detailed reference list or bibliography? & 1 & 1 & 1 \\
\hline & & 10.8 & 10.8 & 10.8 \\
\hline \multirow[t]{13}{*}{ Accuracy } & Does the item have a clearly stated aim or brief? & 1 & 1 & 1 \\
\hline & If so, is this met? & 1 & 1 & 1 \\
\hline & Does it have a stated methodology? & 1 & 0 & 0 \\
\hline & If so, is it adhered to? & 1 & 0 & 0 \\
\hline & Has it been peer-reviewed? & 0 & 0 & 0 \\
\hline & Has it been edited by a reputable authority? & 0 & 0 & 0 \\
\hline & $\begin{array}{l}\text { Supported by authoritative, documented references or credible } \\
\text { sources? }\end{array}$ & 1 & 1 & 1 \\
\hline & Is it representative of work in the field? & 1 & 1 & 1 \\
\hline & If No, is it a valid counterbalance? & 0 & 0 & 0 \\
\hline & Is any data collection explicit and appropriate for the research? & 0 & 0 & 0 \\
\hline & $\begin{array}{l}\text { If the item is a secondary material (e.g. a policy brief of a technical } \\
\text { report), refer to the original. }\end{array}$ & 1 & 1 & 1 \\
\hline & Is it an accurate, unbiased interpretation or analysis? & 1 & 0 & 0 \\
\hline & & 28.8 & 18.0 & 18.0 \\
\hline \multirow[t]{2}{*}{ Coverage } & Are any limits clearly stated? & 0 & 1 & 1 \\
\hline & & 0 & 0 & 0 \\
\hline \multirow[t]{3}{*}{ Objectivity } & $\begin{array}{l}\text { Opinion, expert or otherwise, is still opinion: is the author's } \\
\text { standpoint clear? }\end{array}$ & 1 & 1 & 1 \\
\hline & Does the work seem to be balanced in presentation? & 1 & 1 & 1 \\
\hline & & 7.2 & 7.2 & 7.2 \\
\hline \multirow[t]{4}{*}{ Date } & Does the item have a clearly stated date related to content? & 1 & 1 & 1 \\
\hline & $\begin{array}{l}\text { If no date is given, but can be closely ascertained, is there a valid } \\
\text { reason for its absence? }\end{array}$ & 0 & 0 & 0 \\
\hline & $\begin{array}{l}\text { Check the bibliography: have key contemporary materials been } \\
\text { included? }\end{array}$ & 1 & 1 & 1 \\
\hline & & 7.2 & 7.2 & 7.2 \\
\hline \multirow[t]{8}{*}{ Significance } & $\begin{array}{l}\text { Is the item meaningful? (this incorporates feasibility, utility and } \\
\text { relevance) }\end{array}$ & 1 & 1 & 1 \\
\hline & Does it add context? & 1 & 1 & 1 \\
\hline & Does it enrich or add something unique to the research? & 1 & 1 & 1 \\
\hline & Does it strengthen or refute a current position? & 1 & 1 & 1 \\
\hline & Would the research area be lesser without it? & 1 & 1 & 1 \\
\hline & Is it integral, representative, typical? & 1 & 1 & 1 \\
\hline & $\begin{array}{l}\text { Does it have impact? (in the sense of influencing the work or } \\
\text { behaviour of others) }\end{array}$ & 1 & 1 & 1 \\
\hline & & 25.2 & 25.2 & 25.2 \\
\hline Total scores & & 79.2 & 69.4 & 69.4 \\
\hline
\end{tabular}

TABLE 5b: Summary of quality assessment report of included studies from grey literature (AACODS)

\begin{tabular}{llcc}
\hline Author/organisation & Country & Quality score & Quality index score \\
\hline IrSPEN Special Report No. 1, 2013 & Ireland & 79.2 & 0.79 \\
National DoH, EN, 2016 & South Africa & 69.4 & 0.69 \\
National DoH, PN, 2017 & South Africa & 69.4 & 0.69 \\
\hline
\end{tabular}

$\mathrm{EN}$, enteral nutritional therapy; PN, parenteral nutritional therapy.

secondary analysis of a prospective observational cohort study data from Ireland (Rice Niamh 2013). Of the 19 studies, 10 studies discussed guideline implementation on mechanically ventilated critically ill adults (Bousie et al. 2016; Cahill et al. 2010a; Compton et al. 2014; Dervan et al. 2012; Heyland et al. 2004; 2015; Quenot et al. 2010; Rice Niamh 2013; Sungur et al. 2015; Wang et al. 2017). Eleven of the included primary studies were conducted in tertiary institutions of which nine were university or teaching hospitals (Barr et al. 2004; Bousie et al. 2016; Cahill et al. 2010a; Compton et al. 2014; Dervan et al. 2012; Kim et al.
2017; Mackenzie et al. 2005; Pasinato et al. 2013; Sungur et al. 2015; Quenot et al. 2010; Wang et al. 2017). The three from the grey literature were developed at national levels of respective countries (National Department of Health 2016, 2017; Rice Niamh 2013). Although many studies represented both types of nutritional therapy practice guidelines, the majority $(n=17)$ represented $\mathrm{EN}$, either alone $(n=8)$ or combined with parenteral nutrition $(n=9)$, while nine reported on PN combined with EN and $(n=2)$ (National Department of Health 2017; Rice Niamh 2013) focused on PN only CPGs.

\section{Thematic findings}

The studies have shown that despite the important benefits and positive influence of nutritional therapy guidelines on nutritional practices and clinical course of critical illness, factors exist that hinder their implementation. Therefore, the themes that emerged in this review are discussed under two 
TABLE 6: Descriptive characteristics of the included studies.

\begin{tabular}{ll}
\hline Author, year and country of origin & Aim or focus of the study and setting \\
\hline $\begin{array}{l}\text { Quasi-experimental study } \\
\text { Pakistan et al. 2015, }\end{array}$ & $\begin{array}{l}\text { To determine the effect of the enteral } \\
\text { nutrition algorithm on nutritional } \\
\text { support in critically ill medical patients } \\
\text { in a medical ICU of a university } \\
\text { hospital. }\end{array}$
\end{tabular}

\section{Prospective designs}

Barr et al. 2004,

United States of America

Cahill et al. 2010a

Canada

Dervan, 2012,

United States of America

Dobson and Scott 2007 United Kingdom

Heyland et al. 2004 United States of America

Heyland, 2015, Canada
Determine if protocol use leads to increased EN, earlier feeding and improved outcomes in medical-surgical ICUs of two teaching hospitals. and determine 'best achievable' practice relative to evidence-based university hospitals adult medical ICU.

See possibility to reduce the incidence of overfeeding by implementation of 'weaning' protocol in a10-bed, medsurgical, adult ICU of a tertiary referral teaching hospital.

Determine how reliable the updated CU nurse-led enteral feeding protocol was in medical-surgical ICUs.

Test the hypothesis that ICU consistent with the guidelines would have greater success with EN. Intensive care unit affiliated with a registered dietician.

Describe experience with implementing protocol and the observed improvements in nutrition intake in an ICU with a multidisciplinary team.
Describe current nutrition practices Critical Care Nutrition CPGs in
Results on guideline implementation

40 mechanically ventilated patients divided into two equal groups of $20(50 \%)$ each. Energy intake of study group was $62 \%$ of the prescribed energy requirement on the 1 st, $68.5 \%$ on the 2 nd and $63 \%$ on the 3 rd day whereas in the historical group $38 \%, 56.5 \%$ and $60 \%$ of the prescribed energy requirement were met, respectively. Consumed energy of the historical group on the $1 \mathrm{st}$, 2 nd and $3 \mathrm{rd}$ day was significantly different $(p=0.020)$.

200 critically ill adult patients who remained nil per os (NPO) $>48 \mathrm{~h}$ after admission to the ICU. 100 patients were enrolled into the pre-implementation group, and 100 patients were enrolled into the postand 100 patients were enrolled into the post increased in post-implementation compared to preimplementation ( $78 \%$ vs. $68 \%$, respectively).

The average use of motility agents and small bowel feeding in mechanically ventilated patients who had high gastric residual volumes was $58.7 \%$ (site average range, $0 \%-100 \%$ ) and $14.7 \%$ (site average average range, $\%-100 \%$ ) and $14.7 \%$ (site avera range, $0 \%-100 \%$ ), respectively. There was poor EN formulas enriched with fish oils, glutamine EN formulas enriched with fish oils, glutamine supplementation, timing of supplemental pare
nutrition and avoidance of soybean oil-based nutrition and avoidance of soybean oil-based
parenteral lipids. Average nutritional adequacy was $59 \%$ (site average range, $20.5 \%-94.4 \%$ ) for energy and $60.3 \%$ (site average range, $18.6 \%$ $152.5 \%$ ) for protein.

The study was conducted in patients who were mechanically ventilated for more than $72 \mathrm{~h}$ and receiving nutrition support. Overfeeding noted mor frequently than underfeeding prior to protocol us ( $24.6 \%$ vs. $19.5 \%$ of feeding days) and significantly more often on days when patients were fed by a combination of routes $(p<0.05)$. Post protocol, the incidence of overfeeding reduced almost threefold to $9.1 \%(p<0.001)$, and feeding via a combination of routes no longer a significant cause. Underfeeding did not change, and patients being adequately fed increased from $56 \%$ to $71 \%(p<0.001)$. Postincreased from $56 \%$ to $71 \%(p<0.001)$. Postimplementation, overfeeding reduced by threefold, being adequately fed.

Patients who remained PNO $>48 \mathrm{~h}$ after their admission to the ICU participated in the study. In all, $90 \%(n=43)$ of referrals received by the dietitian met the referral criteria. Absolute compliance with patients receiving correct typ and volumes of feed, with a correct feed prescription and an accurate documented weight was just $2 \%$ and an accurate documented weight was just $2 \%$ $(n=1)$. Despite this finding, $60 \%$ of patients were
actually receiving the correct feed regimen. Absolute actually receiving the correct feed regimen. Absolute
adherence to the nurse-led EN feeding algorithm adherence
was $100 \%$.

All ICU patients who were in ICU for $72 \mathrm{~h}$ and had been mechanically ventilated for $48 \mathrm{~h}$ were observed. (average $43.0 \%$ ). Intensive care units with a greater (average $43.0 \%$ ). Intensive care units with a greater than median utilisation of parenteral nutrition enteral nutrition ( 32.9 vs. $52.7 \%, p<0.0001$ ). Intensive care units that used a feeding protocol tended to have a higher adequacy of enteral nutrition than those that did not ( 44.9 vs. $38.5 \%, p=0.03$ ). Intensive care units that were more consistent with the Canadian CPGs were more likely to successfully feed patients via enteral nutrition.

Participants were patients who were mechanically ventilated prior to ICU admission or within the first $48 \mathrm{~h}$, who stayed in the ICU for at least $72 \mathrm{~h}$. Patients at PEP uP sites received $60.1 \%$ of their prescribed energy requirements from EN compared to $49.9 \%$ of patients from control hospitals $(p=0.02)$. In addition, patients in PEP uP protocol sites received more protein from EN $(61.0 \%$ vs. $49.7 \%$ of prescribed amounts; $p=0.01$ ), were more likely to receive protein supplements ( $71.8 \%$ vs. $47.7 \% ; p=0.01)$ and were more likely to receive > $47.7 \% ; p=0.01)$ and were more likely to receive $>$
$80 \%$ of their protein requirements by day $3(46.1 \%$ vs. $29.3 \% ; p=0.05$ ) compared to patients in control vs. $29.3 \%$;
hospitals.
Conclusions

Use of standard algorithms for EN may be an effective way to meet the nutritional requirements of patients. The study showed that historical group patients required more nutrition than the intervention group.

Protocol use increased the patients receiving $\mathrm{EN}$ and shortened mechanical ventilation time. About $27 \%$ of patients died in the preimplementation group and 30\% died post-implementation.

There is a similar performance gap with respect to pharmaconutrition. Large gaps exist between many recommendations and actual practice with resultant suboptimal nutrition therapy.

A 'weaning' protocol helps to improve adequate feeding for energy in critically ill patients. Significant causes of underfeeding include Gl intolerance, causing interruption for procedures.

Nurse-led feeding algorithm reduced the input of a dietitian on patient feeding algorithm use and empowered nurses to timeouly mower muses to timeouly start NS and safely advance EN the input of a dietician.

Consistency with CPGs may translate into better outcomes for critically ill patients receiving nutrition support. Adoption of the Canadian CPGs should lead to improved nutrition support practice in intensive care units.

Increased nutrition adequacy could be causally related to improved clinical outcomes of critically ill patients.

In the real-life setting, the PEP uP protocol can improve the delivery of EN to critically ill patients. 
TABLE 6 (Continues...): Descriptive characteristics of the included studies.

Author, year and country of origin Aim or focus of the study and setting

Pasinato, 2013,

Brazil

Evaluate the compliance of septic patients' nutritional management with enteral nutrition guidelines for critically ill patients. Public, university, and tertiary hospital.
Quenot et al. 2010,

England

Wøien and Bjørk 2006,

Norway
Assess adherence to clinical practice guidelines and investigate factors leading to non-adherence. University and/or regional hospitals and general (non-academic) hospitals, mixed medico-surgical and medical ICUs.

Test whether a feeding algorithm could improve the nutritional support of intensive care patients. An ICU staffed for caring for seven patients.

\section{Results on guideline implementation}

The study was conducted on ICU septic patients, age $\geq 18$ years. The patients had a mean age of $63.4 \pm$ 15.1 years, were predominantly male, wer diagnosed predominantly with septic shock (56.5\%), had a mean intensive care unit stay of 11 (7.2-18.0) days, had $8.2 \pm 4.2$ SOFA and $24.1 \pm 9.6$ APACHE II scores and had $39.1 \%$ mortality. Enteral nutritional therapy was initiated early in $63 \%$ of the patients. Approximately $50 \%$ met the caloric and protein goals on the 3rd day of ICU stay, a percentage that decreased to $30 \%$ on day 7 .

Patients receiving mechanical ventilation and without contraindication to initiation of enteral nutrition were included in this study. The median ratio of prescribed or required calories per day was 43 [37-54] at day 1 and increased until day 7 . From day 4 until the end of the study, the median ratio was $>80 \%$. The median ratio of delivered/prescribed per day was $>80 \%$ fo all 7 days from the start of enteral nutrition. $A$ oo all 7 days from the start of $(>80 \%)$ and calories prescribed/required $(>80 \%)$ notably after $72 \mathrm{~h}$.

The study participants were patients $20-70$ years old who were expected to stay longer than 4 days in ICU. Patients in the intervention group were both prescribed and actually received significantly larger amounts of nutrients than patients in the control amounts of nutrients than patients in the control
group. They also received a larger proportion of their nutrients in the form of EN. In addition, the nutrients in the form of EN. In addition, the
nutritional support algorithm led to greater nutritional support algorithm led to greater
consistency in nursing practices with respect to consistency in nursing practices with respect to
aspiration of gastric content and rate of increment in enteral feeding. Nutrition delivery was higher in intervention group. The algorithm encourages early initiation and rapid increment of NS.

\section{Retrospective studies}

Bousie et al. 2016

Europe

Compton et al. 2014,

United States of America

Kim, 2017,

Asia

Kiss, 2012,

Switzerland
Address effects of protocol use on energy and protein adequacy, electrolyte abnormalities, glucose control, staff workload and clinical outcome. Mixed medical-surgical ICU in a tertiary university-affiliated teaching hospital.

total, 146 mechanically ventilated patients were included ( 73 patients before and 73 patients after implementation). Before implementation more implementation). Before implementation more $>110 \%$ of target) than after implementation (durin $2-7$ days: $12 \%$ vs. $3 \%, p=0.029$ ) without significant 2-7: $1.18 \mathrm{~g} / \mathrm{kg}$ vs. $1.08 \mathrm{~g} / \mathrm{kg}, p=0.09$ ). After implementation only significantly more patients were fed on target on day $6(47 \%$ vs. $67 \%, p=0.028)$. Less electrolyte imbalance post-implementation, nurses' satisfaction improved post protocol and dietitians' daily workload decreased.

Mechanically ventilated patients, treated in the ICU for a minimum of 5 days were the study participants. After EN protocol implementation EN was started significantly earlier $(p=0.007)$, and EN goals were reached significantly faster ( 6 vs. 10 days, $p<0.001$ ) than before. Prescription of EN on the 1st day of mechanical ventilation increased from $38 \%$ before to $54 \%$ after $(p=0.03)$ implementation of the protocol. Prescribed and delivered nutrition doses on the first 2 days of mechanical ventilation increased significantly $(p<0.001)$ after the protocol was implemented. Nasojejunal feeding tubes were used in $52 \%$ of patients before and $56 \%$ of patients after protocol implementation $(p=0.63)$. Jejunal tubes were placed earlier after the protocol was
implemented than before (median 5 vs. 6.5 days), and when a jejunal tube was in place, feeding goals were reached faster (median 2 vs. 3 days, $p=0.002$ ).

A total of $270 \mathrm{ICU}$ adult patients were included, 134 patients before implementation and 136 after implementation of the protocol. Enteral nutritional therapy was initiated earlier ( $35.8 \mathrm{vs} .87 .1 \mathrm{~h}$, $p=0.001)$ and more patients received $\mathrm{EN}$ within $24 \mathrm{~h}(59.6 \%$ vs. $41.0 \%, p=0.002)$ after implementation of the protocol. Two cohorts of critically ill patients before $(n=56)$
and after $(n=56)$ implementation of an algorithm and after $(n=56)$ implementation of an algorithm
based on the guidelines published by the Society of based on the guidelines published by the Society of
Critical Care Medicine and the American Society for Parenteral and Enteral Nutrition guidelines was observed. Significant differences were noticed between the groups for the mean delivery of total energy in the pre- vs. post-implementation $p<0.001$ ) There were significant differences between groups for the mean delivery of total energy in the pre- vs. postimplementation group. $2-7$ days: $12 \%$ vs. $3 \%, p=0.029$ ) without significant
reduction of protein intake (daily means during day

\section{Conclusions}

Significant number of septic patients was observed on EEN but caloric and protein goals at day 3 in ICU were met by only $50 \%$ a percentage that decreased at day 7 .

It was not possible, however, to show a statistically significant association between meeting the goals and the length of hospital stay, mortality or use of MV.

Variables influencing EN and contributing to non-adherence to CPGs: hospital type, local protocol, sedation, vasoactive drugs, number of interruptions and GRV measurement.

Satisfactory translation of research and recommendations for $E N$ into proctice practice was observed, but there is approach.

Nurses acted less arbitrarily in executing nutrition orders and aspiration routines for the intervention group. The algorithm intervention group. The algorithm patients' nutrition in several areas.

Improved non-significant outcome trends for hospital LOS and for ICU and hospital mortality. Mortality reduction, preventing overfeeding without affecting protein intake and less electrolyte abnormalities were observed after mplementation

Implementation of an NS protoco significantly improved the EN provision in ICU patients receiving mechanical ventilation. Jejunal feeding tubes were necessary in more than half of the patients, and with a jejunal feeding tube in place, feeding goals were reached rapidly. However, the retrospective approach did not allow assessment of appropriateness of clinical decisions and adherence to the developed protocol.

The post-implementation group was given more pro-kinetics and less parenteral nutrition.

EN protocol had beneficial effects: EEN, quick achieving target calories, less frequent PN use, and decreasing GI bleeding and diarrhoea.

This was the first report on algorithm implementation with no dietitian or nutrition support team. Algorithm implementation resulted in improved provision of energy and protein delivery. However, unique dietitian expertise in ICU and specific focus on individualised nutrition support remains ideal and would also increase the adherence to nutrition support guidelines. 
TABLE 6 (Continues...): Descriptive characteristics of the included studies.

\begin{tabular}{|c|c|c|c|}
\hline Author, year and country of origin & Aim or focus of the study and setting & Results on guideline implementation & Conclusions \\
\hline $\begin{array}{l}\text { Mackenzie, 2005, } \\
\text { Canada }\end{array}$ & $\begin{array}{l}\text { Determine whether implementation of } \\
\text { an evidence-based nutrition support } \\
\text { (NS) protocol could improve EN } \\
\text { delivery in a tertiary-care 22-bed } \\
\text { medical-surgical referral ICU. }\end{array}$ & $\begin{array}{l}\text { Adult patients who receive either zero EN or PN were } \\
\text { included in the study. The percentage of patients who } \\
\text { received at least } 80 \% \text { of their estimated energy } \\
\text { requirements in ICU increased from } 20 \% \text { before } \\
\text { implementation of the NS protocol to } 60 \% \text { after } \\
\text { implementation }(p=0.001) \text {. Post-implementation } \\
\text { group received significantly more } \mathrm{kcal} / \mathrm{kg} / \mathrm{d} \text { than the } \\
\text { pre-implementation group }(3.71 \mathrm{kcal} / \mathrm{kg} / \mathrm{d} ; 95 \% \\
\text { confidence interval, } 1.64-5.78 ; p=0.001) \text {. }\end{array}$ & $\begin{array}{l}\text { Reduction in the PN use decreased } \\
\text { in the post-implementation group. } \\
\text { The protocol improved proportion } \\
\text { of patients on EN meeting } \\
\text { calculated nutrition requirements. }\end{array}$ \\
\hline $\begin{array}{l}\text { Wang, 2017, } \\
\text { Taiwan }\end{array}$ & $\begin{array}{l}\text { Compare pre- and post-implementation } \\
\text { outcomes of the feeding protocol, and } \\
\text { evaluate the effects of total energy } \\
\text { delivery on outcomes in these patients } \\
\text { in a tertiary medical centre and general } \\
\text { hospital. }\end{array}$ & $\begin{array}{l}\text { The study was conducted on TBI patients, older than } \\
20 \text { years, on EN only, and receiving at least } 48 \mathrm{~h} \text { of } \\
\text { mechanical ventilation. Compared with delayed } \\
\text { feeding, early feeding was associated with a } \\
\text { significant reduction in the rate of mortality (relative } \\
\text { risk }=0.35 ; 95 \% \mathrm{Cl}, 0.24-0.50) \text {, poor outcome (RR }= \\
0.70 ; 95 \% \mathrm{Cl}, 0.54-0.91 \text { ) and infectious complications } \\
(\mathrm{RR}=0.77 ; 95 \% \mathrm{Cl}, 0.59-0.99) \text {. Compared with } \\
\text { enteral nutrition, parenteral nutrition showed a slight } \\
\text { trend of reduction in the rate of mortality (RR }=0.61 \text {; } \\
95 \% \mathrm{Cl}, 0.34-1.09 \text { ), poor outcome (RR }=0.73 ; 95 \% \mathrm{Cl} \text {, } \\
0.51-1.04 \text { ) and infectious complications (RR }=0.89 ; \\
95 \% \mathrm{Cl}, 0.66-1.22) \text {. }\end{array}$ & $\begin{array}{l}\text { Implementation of the feeding } \\
\text { protocol could improve energy } \\
\text { intake for critically ill patients; } \\
\text { however, it had no beneficial } \\
\text { effects on reducing the ICU } \\
\text { mortality rate. }\end{array}$ \\
\hline \multicolumn{4}{|c|}{ Literature review and expert opinion studies } \\
\hline $\begin{array}{l}\text { National Department of Health 2016, } \\
\text { Republic of South Africa }\end{array}$ & $\begin{array}{l}\text { Provides guidelines and practical } \\
\text { strategies for successful } \\
\text { implementation of EN regime in adult } \\
\text { patients in all public healthcare } \\
\text { facilities }\end{array}$ & $\begin{array}{l}\text { Recommendations on nutrition assessment, EN use, } \\
\text { handling of complications, monitoring and evaluation } \\
\text { of EN for all adult patients in all public healthcare } \\
\text { facilities. }\end{array}$ & $\begin{array}{l}\text { Once tolerance is established, } \\
\text { there is no need for frequent } \\
\text { GRV measurement to avoid } \\
\text { inappropriate interruption. } \\
\text { A multidisciplinary approach } \\
\text { to ensure effective assessment } \\
\text { and treatment interventions is } \\
\text { needed. }\end{array}$ \\
\hline $\begin{array}{l}\text { National Department of Health 2017, } \\
\text { Republic of South Africa }\end{array}$ & $\begin{array}{l}\text { Provides recommendations based on } \\
\text { the best practice of PN management by } \\
\text { care workers for all adult patients in all } \\
\text { public healthcare facilities. }\end{array}$ & $\begin{array}{l}\text { Recommendations for } \mathrm{PN} \text {, the roles and } \\
\text { responsibilities of the nutrition therapy team in all } \\
\text { adult patients receiving parenteral nutrition therapy } \\
\text { in government health facilities. }\end{array}$ & $\begin{array}{l}\text { Monitoring ensures adherence to } \\
\text { national guidelines. Evaluation } \\
\text { allows comprehensive assessment } \\
\text { and PN documentation. Parenteral } \\
\text { nutritional therapy CPG should } \\
\text { ensure evidence-based and } \\
\text { standardised PN prescriptions. }\end{array}$ \\
\hline Rice 2013, Republic of Ireland & $\begin{array}{l}\text { Reviews HPN use and practices, makes } \\
\text { proposals for safe, high quality care } \\
\text { and equitable access for all suitable } \\
\text { candidates in the community health } \\
\text { sector. }\end{array}$ & $\begin{array}{l}\text { Deficits identified in coordination, resource planning } \\
\text { and clinical governance of the HPN service provision } \\
\text { for adult patients who had been mechanically } \\
\text { ventilated within } 48 \mathrm{~h} \text { of ICU admission and had been } \\
\text { in the ICU for more than } 72 \mathrm{~h} \text {. }\end{array}$ & $\begin{array}{l}\text { GPs and primary care team } \\
\text { members lack specialist knowledge } \\
\text { of HPN. Recommend for access for } \\
\text { all patients in need of HPN. }\end{array}$ \\
\hline
\end{tabular}

EN, enteral nutrition; PN, parenteral nutrition; CPGs, clinical practice guidelines; ICU, intensive care unit; LOS, length of stay; NS, nutritional support.

headings: the efficacy and impact of nutritional therapy practice guidelines and factors influencing implementation (see Table 7).

\section{The efficacy and impact of nutritional therapy guidelines}

The studies have provided information on the implementation of nutritional therapy practice guidelines in the form of EN and PN CPGs, protocols and algorithms. Out of five studies that reported on CPGs, three of them were discussing CPGs for EN (National Department of Health 2016; Pasinato et al. 2013; Quenot et al. 2010). According to the authors, EN CPGs can improve patient clinical outcome, improve quality of life and reduce patient care costs (National Department of Health 2016:8) when implemented. A significant number of septic patients were started early on $\mathrm{EN}$, and there was satisfactory translation of research and recommendations into practice (Quenot et al. 2010:1). EN protocols were also found to increase EN use, early EN, reaching of feeding goals and shortened mechanical ventilation time but had no beneficial effects on reducing mortality (Barr et al. 2004:1454; Kim et al. 2017:34; Mackenzie et al. 2005:77). For example, in a study aimed at finding out if EN protocols could improve clinical outcomes, it was found that almost the same number of deaths occurred in both the control and intervention groups, $27 \%$ and $30 \%$, respectively (Barr et al. 2004:1454). On the other hand, implementation of algorithms was found to be the standard intervention to operationalise guidelines at the bedside and achieve nutritional requirements (Dobson \& Scott 2007:120; Kiss et al. 2012:793; Sungur et al. 2015:813; Wøien \& Bjørk 2006:168). Dobson and Scott (2007:120) added that the nurse-led algorithm promoted best practicebased referral criteria so that patients at nutritional risk were referred for tailored dietetic assessment, and also empowered nurses to start and advance EN timeouly and safely without dietician input. Practice guidelines are based on research evidence and contain therapy-specific recommendations intended to minimise variations in nutrition practices (Kiss et al. 2012:793). Consistent nutritional practices improve the provision of nutritional therapy, improve patient care and thus clinical outcomes of critical illness, costs and quality of life (Rice Niamh 2013:12).

\section{Factors that influence nutrition therapy guidelines implementation}

The development and availability of practice guidelines does not necessarily result in a change in clinical practice. Several factors must be considered to successfully implement guidelines (Kiss et al. 2012:793). Factors that influence successful guidelines implementation include awareness of existing guidelines, consensus among clinicians on which guidelines to adopt, and finally adherence by the practitioner to the guidelines (Kiss et al. 2012:793). A multidisciplinary 


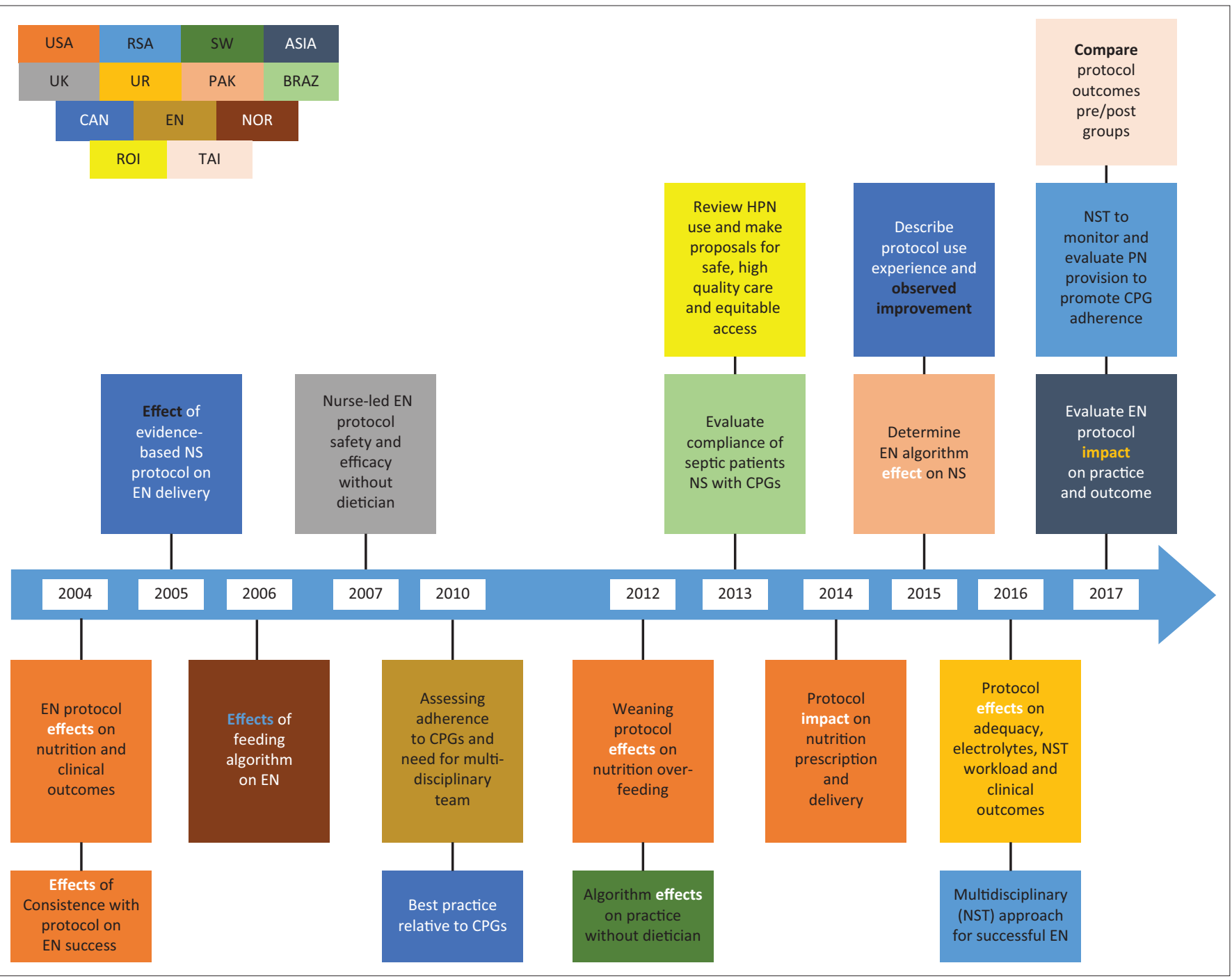

FIGURE 2: Summarised focus of included studies.

TABLE 7: Themes generated from thematic analysis of results.

\begin{tabular}{|c|c|c|}
\hline Final themes & Meaning & Code list \\
\hline \multirow[t]{2}{*}{$\begin{array}{l}\text { The efficacy and impact of nutritional } \\
\text { therapy practice guidelines }\end{array}$} & $\begin{array}{l}\text { How effective or useful guidelines } \\
\text { implementation was (efficacy) }\end{array}$ & $\begin{array}{l}\text { - Enteral nutrition (EN) protocols increase EN use, early EN, reaching of feeding goals and } \\
\text { shortened mechanical ventilation time. } \\
\text { - Nurse-led algorithm promoted best practice-based referral criteria so that patients at } \\
\text { nutritional risk were referred for tailored dietetic assessment, empowered nurses to start and } \\
\text { advance EN timely and safely without dietician input. } \\
\text { - A significant number of septic patients were started early on EN and there was satisfactory } \\
\text { translation of research and recommendations into practice. }\end{array}$ \\
\hline & $\begin{array}{l}\text { The overall impact of guideline } \\
\text { implementation on patient outcomes } \\
\text { and health system (impact) }\end{array}$ & $\begin{array}{l}\text { - Practice guidelines minimise variations in nutrition practices. } \\
\text { - Clinical practice guidelines (CPGs) can improve patient clinical outcome, improve quality of life } \\
\text { and reduce patient care costs. } \\
\text { consistent nutritional practices improve the provision of nutritional therapy, improve patient } \\
\text { care and thus clinical outcomes of critical illness, costs and quality of life. }\end{array}$ \\
\hline \multirow[t]{2}{*}{$\begin{array}{l}\text { Factors influencing implementation of } \\
\text { nutritional therapy practice guidelines }\end{array}$} & Positive factors & $\begin{array}{l}\text { - Factors influencing successful guidelines implementation include awareness of existing } \\
\text { guidelines, consensus among clinicians on which guidelines to adopt. } \\
\text { - A multidisciplinary team involvement, staff education and training, active and passive } \\
\text { reminders, presentations by opinion leaders, and discussions during rounds are also } \\
\text { recommended for successful guidelines implementation. }\end{array}$ \\
\hline & Negative factors & - Important deficits include poor coordination, resource planning and clinical governance. \\
\hline
\end{tabular}

team involvement, staff education and training, active and passive reminders, presentations by opinion leaders and discussions during rounds are also recommended for guidelines implementation (Kiss et al. 2012:793; Rice Niamh 2013). Other important deficits that have been identified in the nutritional service provision for adult patients include coordination, resource planning and clinical governance (Rice Niamh 2013:12).

\section{Quality assessment results}

The results of the MMAT tool show that the published included studies scored between $75 \%$ and $100 \%$ on the quality score, with five of the studies being $75 \%$ and 11 being $100 \%$. The quality scores of the grey literature studies, AACODS, ranged between six (National Department of Health 2016, 2017) and seven (Rice Niamh 2013), which is 
moderate to high quality. According to the grades of recommendations and levels of evidence, overall, the studies are grade B, IIa and Ilb level of evidence as they were nonrandomised controlled studies and at least one quasiexperimental study (Mesejo et al. 2011:3). Tables 4, 5a and 5b present quality appraisal results.

\section{Discussion}

This study aimed at examining literature on the extent of nutritional therapy practice guidelines and implementation in the management of critically ill adults. Our study found that adherence to CPGs can improve patient clinical outcome, reduce mechanical ventilation time, ICU and hospital length of stay, save healthcare costs and improve quality of life by improving EN practices and facilitating translation of research and recommendation (Mackenzie et al. 2005:74; National Department of Health 2016:8; Pasinato et al. 2013:22; Quenot et al. 2010:1). This is a crucial finding, particularly in low- and middle-income countries with resource restrictions and a growing burden of critical illness (Gordon, Allorto \& Wise 2015:1). Of concern is to notice that 11 of the primary studies were conducted in tertiary institutions and only one compared guideline implementation between academic and community hospitals (which sometimes do not have an ICU). This is sad as critical illness neither starts nor ends within the four walls of ICU. Acutely ill patients are susceptible to malnutrition, and this is common in critically ill patients, occurring in $30 \%-50 \%$ of hospitalised patients. Malnutrition increases hospital costs and is associated with increased long-term mortality (Wischmeyer 2011). Wischmeyer (2013) reported that a 23-year-old male patient admitted in a small community hospital, complicated on day 3 post-operatively and because he received poor nutrition for a prolonged period, complicated further, was transferred to ICU and died of malnutrition.

In countries such as South Africa, critical care in general faces challenges from changing disease patterns and lack of human and financial resources as these are redirected to primary healthcare and other priorities (Mathivha 2002:1). Unfortunately, the primary care team members and general practitioners lack specialist knowledge, and many hospitals discharging patients on home artificial nutrition do not have a specialist multidisciplinary team (MDTs) (Pasinato et al. 2013; Rice Niamh 2013:29). Another important fact is that most clinicians view nutrition as part of patient care but not as a therapeutic intervention, hence the need for outreach services (Rice Niamh 2013:29).

Although there is growing interest on the implementation of NT practice guidelines in critical care and the practice of providing nutrition to these patients is almost universal, the specifics vary widely from one ICU to another and even among providers (Desai, McClave \& Rice 2014:1148). However, it was interesting to find that nurse-led protocols improved NT practice by $100 \%$ and relieved the workload of the dieticians and other members of the team (Dobson \&
Scott 2007:119). This is in agreement with the view of Mauldin and O'Leary-Kelley (2015:24) that nurses are better positioned to screen patients at risk for malnutrition and to work with members of the multidisciplinary team in implementing nutritional therapy plans. Friesecke et al. (2014:204) also believe that adherence to EN guidelines can be improved if ICU nursing staff is responsible for translating it into action with the help of a written algorithm. However, there is still a need for improved knowledge-to-practice translation for all disciplines of healthcare professionals involved with nutritional care of the critically ill patient (Field et al. 2014:2). Coordination, resource planning and clinical governance have been identified as important deficits that need to be considered in the provision of nutritional therapy in adult patients (Rice Niamh 2013:29).

\section{Strengths}

Our study adopted Arksey and O'Malley's methodological framework, generally recognised as best practice for scoping reviews, and has been adapted to include methodological quality and bias risk assessment. In addition, the included studies scored average or moderate to high in the methodological quality and bias risk assessment, which may help avoid reading of flawed literature and preventing incorporating biased or untrustworthy information into practice. The study also includes non-randomised studies, which are convenient study designs that can suggest possible relationships between the intervention and the outcome. We further searched and included grey literature studies in our review, which is known to reduce publication bias, increase reviews' comprehensiveness and timeliness and foster a balanced picture of available evidence.

\section{Study limitations}

All published studies adopted non-randomised designs, which are often subject to many types of bias and errors and therefore not considered strong study designs. Studies with inadequate or unclear randomisation tend to overestimate treatment effects up to $40 \%$, which can have a negative impact on the results. Furthermore, non-randomised trials may increase selection bias and having another intervention such as mechanical ventilation, as 11 of included studies have, may cause performance bias. One study reported a withdrawal of more than $50 \%$ on day 3 of the study, which means that it had increased attrition bias.

\section{Recommendations Pertaining to research}

Based on the results, this study recommends more studies aimed at evaluating existing guideline recommendations for practicability and the development of implementation strategies or models. Further research is recommended for the development of nurse-led bedside EN algorithms that will incorporate the use of pro-kinetics as a strategy to optimise EN delivery in critically ill adult patients; current guidelines recommend $\mathrm{EN}$ rather than $\mathrm{PN}$. EN restores gut 
motility, maintains gastrointestinal integrity and function, minimises translocation of bacteria, improves wound healing and reduces infection risk. Evidence exists that there is a large gap between many recommendations and actual practice, which calls for more research to tailor international and national guidelines. Furthermore, as it may sometimes be unethical to conduct randomised trials when developing nutritional guidelines, protocols that incorporate use of prokinetics should be considered as a strategy to optimise EN delivery in critically ill adult patients.

\section{Pertaining to practice and policy}

We recommend the development of bedside algorithms focused on EN and including parenteral nutrition as a supplement to improve the delivery of clinical nutrition in critically ill patients. An algorithm is defined as an operational version of a guideline that is adapted to local requirements and easy to apply in clinical practice. It focuses on specific steps of the nutritional therapy process based on patientspecific conditions and objective assessment.

\section{Conclusion}

Studies have debated that, even in circumstances where implementation was less than perfect, significant improvements were still observed in nutritional practices and nutrition outcomes. We suggest that with greater attention to the implementation of all forms of nutritional therapy practice guidelines customised to suit the local or institutional condition and availability of NST, most critically ill patients will receive the prescribed amounts of nutrients. The consequence will be improvement in nutritional therapy practices, nutritional outcomes, clinical outcomes and reduction in healthcare costs. Satisfactory translation of research and recommendations for EN into practice alone is not enough, there is also a need for a multidisciplinary approach.

\section{What this paper adds}

Evidence on the efficacy and impact of nutritional therapy practice guideline recommendations has increased. Despite this increased evidence, nutritional practices remain varied, leading to suboptimal nutrition delivery. When EN protocols and nurse-led algorithms were implemented, adherence to international and national guidelines was almost 100\%, EN was commenced early, nutritional goals were met, mechanical ventilation time decreased. This change in practice allowed the dietitian to dedicate time to more complex cases. Strategies that can enhance adherence to nutritional therapy practice guidelines include structured protocols and algorithms, collaboration, integration, teamwork and fair distribution of resources in the entire trajectory of nutrition care. Whether a patient in need of specialised nutritional therapy is in a tertiary or community health facility should not be an issue. It is the disparities in patient care that should be addressed.

\section{Acknowledgements}

The authors thank the Systematic Reviews Services in the School of Nursing and Public Health, University of KwaZulu-Natal, for the academic support, and the University of KwaZulu-Natal, School of Nursing and Public Health and University Capacity Developmental Programme, for academic and financial support.

\section{Competing interests}

The authors have declared that no competing interests exist.

\section{Authors' contributions}

Both authors contributed equally to this work.

\section{Funding information}

This study was financially supported by the University of KwaZulu-Natal Capacity Developmental Programme.

\section{Data availability statement}

Data sharing is not applicable to this article as no new data were created or analysed in this study.

\section{Disclaimer}

The views and opinions expressed in this article are those of the authors and do not necessarily reflect the official policy or position of any affiliated agency of the authors.

\section{References}

Arksey, H. \& O'Malley, L., 2005, 'Scoping studies: Towards a methodological framework', International Journal of Social Research Methodology 8(1), 19-32, Routledge Taylor \& Francis Group LTD, United Kingdom. https://doi.org/10.1080/1364557032000119616

Barr, J., Hecht, M., Flavin, K.E., Khorana, A. \& Gould, M.K., 2004, 'Outcomes in critically ill patients before and after the implementation of an evidence-based nutritional management protocol', Chest 125(4), 1446-1457. https://doi.org/10.1378/ chest.125.4.1446

Boniatti, M.M., Friedman, G., Castilho, R.K., Vieira, S.R.R. \& Fialkow, L., 2011, 'Characteristics of chronically critically ill patients: Comparing two definitions', Clinics 66(4), 701-704. https://doi.org/10.1590/S1807-59322011000400027

Bousie, E., Van Blokland, D. \& Van Zanten, A.R.H., 2016, 'Effects of implementation of a computerized nutritional protocol in mechanically ventilated critically ill patients: A single-centre before and after study', Clinical Nutrition ESPEN 11, e47-e54. https://doi.org/10.1016/j.clnesp.2015.12.004

Braun, V. \& Clarke, V., 2006, 'Using thematic analysis in psychology', Qualitative Research in Psychology 3(2), 77-101. https://doi.org/10.1191/1478088706qp063oa

Cahill, N.E., Dhaliwal, R., Day, A.G., Jiang, X. \& Heyland, D.K., 2010a, 'Nutrition therapy in the critical care setting: What is "best achievable" practice? An international multicenter observational study', Critical Care 38(2), 395-401.

Cahill, N.E., Narasimhan, S., Dhaliwal, R. \& Heyland, D.K., 2010b, 'Attitudes and beliefs related to the Canadian critical care nutrition practice guidelines: An international survey of critical care physicians and dietitians', Journal of Parenteral and Enteral Nutrition 34(6), 685-696. https://doi.org/10.1177/0148607110361908

Cahill, N.E., Murch, L., Cook, D. \& Heyland, D.K., 2014, 'Implementing a multifaceted tailored intervention to improve nutrition adequacy in critically ill patients: Results of a multicenter feasibility study', Critical Care 18(3), R96. https://doi. org/10.1186/cc13867

Compton, F., Bojarski, C., Siegmund, B. \& Van der Giet, M., 2014, 'Use of a nutrition support protocol to increase enteral nutrition delivery in critically ill patients', American Journal of Critical Care: An Official Publication, American Association of Critical-Care Nurses 23(5), 396-403. https://doi.org/10.4037/ajcc2014140

Dervan, N., Dowsett, J., Gleeson, E., Carr, S., \& Corish, C., 2012, 'Evaluation of overand underfeeding following the introduction of a protocol for weaning from parenteral to enteral nutrition in the intensive care unit', Nutrition in Clinical Practice 27(6), 781-787. https://doi.org/10.1177/0884533612462899

Desai, S.V., McClave, S.A. \& Rice, T.W., 2014, 'Nutrition in the ICU: An evidence-based approach', Chest 145(5), 1148-1157. https://doi.org/10.1378/chest.13-1158 
Dhaliwal, R., Cahill, N., Lemieux, M. \& Heyland, D.K., 2014, 'The Canadian critical care nutrition guidelines in 2013: An update on current recommendations and care nutrition guidelines in 2013: An update on current recommendations and
implementation strategies', Nutrition in Clinical Practice 29(1), 29-43. https://doi. implementation strategies', Nutrition
org/10.1177/0884533613510948

Dobson, K. \& Scott, A., 2007, 'Review of ICU nutrition support practices: Implementing the nurse-led enteral feeding algorithm', Nursing in Critical Care 12(3), 114-123. https://doi.org/10.1111/j.1478-5153.2007.00222.x

Field, B., Booth, A., Ilott, I. \& Gerrish, K., 2014, 'Using the knowledge to action framework in practice: A citation analysis and systematic review', Implementation Science 9(172). https://doi.org/10.1186/s13012-014-0172-2

Friesecke, S., Schwabe, A., Stecher, S.-S. \& Abel, P., 2014, 'Improvement of enteral nutrition in intensive care unit patients by a nurse-driven feeding protocol', Nursing in Critical Care 19(4), 204-210. https://doi.org/10.1111/nicc.12067

Gordon, K., Allorto, N. \& Wise, R., 2015, 'Analysis of referrals and triage patterns in a South African metropolitan adult intensive care service', South African Medical Journal 105(6), 491-495. https://doi.org/10.7196/SAMJ.9007

Heyland, D.K., Dhaliwal, R., Day, A., Jain, M. \& Drover, J., 2004, 'Validation of the Canadian clinical practice guidelines for nutrition support in mechanically ventilated, critically ill adult patients: Results of a prospective observational study', Critical Care Medicine 32(11), 2260-2266. https://doi.org/10.1097/01. CCM.0000145581.54571.32

Heyland, D.K., Dhaliwal, R., Lemieux, M., Wang, M. \& Day, A.G., 2015, 'Implementing the PEP UP protocol in critical care units in Canada: Results of a multicenter quality improvement study', Journal of Parenteral and Enteral Nutrition 39(6), 698-706. https://doi.org/10.1177/0148607114531787

Hirshon, J.M, Risko, N., Calvello, E.J., De Ramirez, S.S., Narayan, M., Theodosis, C. et al., 2013, 'Health systems and services: The role of acute care', Bulletin of the World
Health Organization 91(3), 386-388. https://doi.org/10.2471/BLT.12.112664

Jones, N.E., Dhaliwal, R., Day, A.G., Ouellette-Kuntz, H. \& Heyland, D.K., 2008, 'Factors predicting adherence to the Canadian clinical practice guidelines for nutrition support in mechanically ventilated, critically ill adult patients', Journal of Critical support in mechanically ventilated, critically ill adult patients', Jour
Care 23(3), 301-307. https://doi.org/10.1016/j.jcrc.2007.08.004

Keller, H.H., McCullough, J., Davidson, B., Vesnaver, E., Laporte, M., Gramlich, L. et al., 2015, 'The Integrated Nutrition Pathway for Acute Care (INPAC): Building consensus with a modified Delphi', Nutrition Journal 14(63). https://doi. org/10.1186/s12937-015-0051-y

Kim, H., Stotts, N.A., Froelicher, E.S., Engler, M.M., Porter, C. \& Kwak, H., 2012, 'Adequacy of early enteral nutrition in adult patients in the intensive care unit', Journal of Clinical Nursing 21(19), 2860-2869. https://doi.org/10.1111/j.1365-2702.2012.04218.x

Kim, S.-H., Park, C.-M., Seo, J.-M., Choi M., Lee D.S., Chang, D.K. et al., 2017, 'The impact of implementation of an enteral feeding protocol on the improvement of enteral nutrition in critically ill adults', Asia Pacific Journal of Clinical Nutrition 26(1), 27-35. https://doi.org/10.6133/apjcn.122015.01

Kiss, C.M., Byham-Gray, L. Denmark, R., Loetscher, R. \& Brody, R.A. et al., 2012, 'The impact of implementation of a nutrition support algorithm on nutrition care outcomes in an intensive care unit', Nutrition in Clinical Practice 27(6), 793-801. https://doi.org/10.1177/0884533612457178

Levac, D., Colquhoun, H. \& O'Brien, K.K., 2010, 'Scoping studies: Advancing the methodology', Implementation Science 5(1), 69.

Liberati, A., Altman, D.G., Tetzlaff, J., Mulrow, C., Gøtzsche, P.C., Ioannidis, J.P.A. et al., 2009, 'The PRISMA statement for reporting systematic reviews and metaanalyses of studies that evaluate health care interventions: Explanation and elaboration', PLOS Medicine 6(7), e1000100, 1-28. https://doi.org/10.1371/ journal.pmed.1000100

Mackenzie, S.L., Zygun, D.A., Whitmore, B.L., Doig, C.J. \& Hameed, S.M., 2005 Implementation of a nutrition support protocol increases the proportion of
mechanically ventilated patients reaching enteral nutrition targets in the adult mechanically ventilated patients reaching enteral nutrition targets in the adult
intensive care unit', Journal of Parenteral and Enteral Nutrition 29(2),74-80. intensive care unit', Journal of Parenteral and
https://doi.org/10.1177/014860710502900274

Martindale, R.G., McCarthy, M.S. \& McClave, S.A., 2011, 'Guidelines for nutrition therapy in critical illness: Are not they all the same?', Minerva Anestesiol 77(4), 463-467.

Mathivha, L.R., 2002, 'ICUs worldwide: An overview of critical care medicine in South Africa', Critical Care 6(1), 22. https://doi.org/10.1186/cc1449

Mauldin, K. \& O'Leary-Kelley, C., 2015, 'New guidelines for assessment of malnutrition in adults: Obese critically ill patients', Critical Care Nurse 35(4), 24-30. https://doi. org/10.4037/ccn201588

Mayosi, B.M. \& Benatar, S.R., 2014, 'Health and health care in South Africa-20 years after Mandela', New England Journal of Medicine 371(14), 1344-1353. https:// doi.org/10.1056/NEJMsr1405012

McClave, S.A., Taylor, B.E., Martindale, R.G., Warren, M.M., Johnson, D.R. \& Branschweig, C. et al., 2016, 'Guidelines for the provision and assessment of nutrition support therapy in the Adult Critically III Patient Society of Critical Care Medicine (SCCM) and American Society for Parenteral and Enteral Nutrition (ASPEN)', Journal of Parenteral and Enteral Nutrition 40(2), 159-211. https://doi.org/10.1177/0148607115621863

Mesejo, A., Vaquerizo Alonso, C., Acosta Escribano, J., Ortiz Leybad, C. \& Montejo Gonzáleze, J.C., 2011, 'Guidelines for specialized nutritional and metabolic support in the critically-ill patient: Update. Consensus SEMICYUC-SENPE: Introduction and methodology', Nutricion Hospitalaria 26(2), 1-6. https://doi.org/10.1016/S0210 5691(11)70001-8
Moher, D., Liberati, A. \& Tetzlaff, J., 2009, 'Preferred reporting items for systematic reviews and meta-analyses: The PRISMA statement', PLoS Medicine 6(7), 1-6. https://doi.org/10.1371/journal.pmed.1000097.

National Collaborating Centre for Acute Care, 2006, Nutrition support for adults: Oral nutrition support, enteral tube feeding and parenteral nutrition, National Collaborating Centre for Acute Care, London, UK.

National Department of Health, 2017, in Health Do (ed.), National parenteral nutrition practice guidelines for adults: A long and Healthy Life for All South Africans, pp. 1-35, Government Printers, National Department of Health, Pretoria.

Noyes, J. \& Lewin, S., 2011, 'Chapter 5: Extracting qualitative evidence', in J. Noyes, A. Booth, K. Hannes, A. Harden, J. Harris, S. Lewin, et al. (eds.), Supplementary guidance for inclusion of qualitative research in Cochrane systematic reviews of interventions, Chapter 5, pp. 1-24, Cochrane Collaboration Qualitative Methods Group, Version 1.

Pace, R., Pluye, P., Bartlett, G., Macaulay, A.C., Salsberg, J., Jagosh, J. et al., 2012 'Testing the reliability and efficiency of the pilot Mixed Methods Appraisal Tool (MMAT) for systematic mixed studies review', International Journal of Nursing Studies 49(1), 47-53. https://doi.org/10.1016/j.ijnurstu.2011. 07.002

Padilla Fuentes, P., Martínez, G., Vernooij, R.W.M., Bonfill Cospa, X., \& Alonso-Coello, P., 2016, 'Nutrition in critically ill adults: A systematic quality assessment of clinica practice guidelines', Clinical Nutrition (Edinburgh, Scotland), 35(6), 1219-1225. https://doi.org/10.1016/j.clnu.2016.03.005

Pasinato, V.F., Berbigier, M.C., Rubin, B.D.A., Castro, K., Moraes, R.B. \& Schweigert Perry, I.D., 2013, 'Enteral nutritional therapy in septic patients in the intensive care unit: Compliance with nutritional guidelines for critically ill patients', Revista Brasileira De Terapia Intensiva 25(1), 17-24. https://doi.org/10.1590/S0103507X2013000100005

Peev, M.P., Yeh, D.D., Quraishi, S.A., Osler, P., Chang, Y. \& Gillis, E. et al., 2015, 'Causes and consequences of interrupted enteral nutrition a prospective observational study in critically ill surgical patients', Journal of Parenteral and Enteral Nutrition 39(1), 21-27. https://doi.org/10.1177/0148607114526887

Pluye, P., Robert, E., Cargo, M., Bartlett, G., O'Cathain, A., Griffiths, F. et al., 2011 'Proposal: A mixed methods appraisal tool for systematic mixed studies reviews', viewed 16 March 2018, from http://www.webcitation.org/5tTRTc9yJ

Quenot, J.-P., Plantefeve, G., Baudel, J.-L., Camilatto, I., Bertholet, E., Cailliod, R. et al ., 2010, 'Bedside adherence to clinical practice guidelines for enteral nutrition in 2010, 'Bedside adherence to clinical practice guidelines for enteral nutrition in critically ill patients receiving mechanical ventilation: A prospective, multi-centre,
observational study', Critical Care (London, England) 14(2), R37-R37. https://doi. observational study,
org/10.1186/cc8915

Rice Niamh, DJaOHC, 2013, A review of home parenteral nutrition in Ireland: Recommendations for action, IrSPEN's Standards and Guidelines Committee, Recommenc.
Ireland.

Ridley, E., Gantner, D. \& Pellegrino, V., 2015, 'Nutrition therapy in critically ill patients - A review of current evidence for clinicians', Clinical Nutrition 34(4), 565-571. https://doi.org/10.1016/j.clnu.2014.12.008

Sungur, G., Sahin, H. \& Tasci, S., 2015, 'The effects of implementing a nutritional support algorithm in critically ill medical patients', Journal of Pakistan Medical Association 65(8), 810-814.

Taylor, B.E., McClave, S.A., Martindale, R.G., Warren, M.M., Johnson, D.R., Braunschwieg, C. et al., 2016, 'Guidelines for the provision and assessment of nutrition support therapy in the adult critically ill patient: Society of Critical Care Medicine (SCCM) and American Society for Parenteral and Enteral Nutrition (ASPEN)', Critical Care Medicine 44(2), 390-438. https://doi.org/10.1097/ CCM.0000000000001525

Wang, C.-Y., Huang, C.-T., Chen, C.-H., Chen, M.F., Ching, S.-L. \& Huang, Y.-C., 2017 'Optimal energy delivery, rather than the implementation of a feeding protocol, may benefit clinical outcomes in critically ill patients', Nutrients, 9(5), 527. https:// doi.org/10.3390/nu9050527

Warren, M., McCarthy, M.S. \& Roberts, P.R., 2016, 'Practical application of the revised guidelines for the provision and assessment of nutrition support therapy in the adult critically ill patient', Nutrition in Clinical Practice 31(3), 334-341.

WHO, 2016, Accelerating nutrition improvements: Best practices in scaling up nutrition actions, Examples from Ethiopia, Uganda and the United Republic of Tanzania, World Health Organization, Geneva. Licence: CC BY-NC-SA 3.0 IGO

WHO, 2017, The double burden of malnutrition, Policy Brief, Geneva.

Windle, E.M., 2009, 'Dietetic service provision for burn care in the United Kingdom: Are nutrition support standards being met?', Journal of Human Nutrition and Dietetics 22(4), 317-323. https://doi.org/10.1111/j.1365-277X.2009. and Dietet

Wischmeyer, P.E., 2011, 'Malnutrition in the acutely ill patient: Is it more than just protein and energy?', South African Journal of Clinical Nutrition 24(S1), 1-7. https://doi.org/10.1080/16070658.2011.11734372

Wischmeyer, P.E., 2013, 'The evolution of nutrition in critical care: How much, how soon?', Critical Care 17(Suppl 1), S7.

Wøien, H. \& Bjørk, I.T., 2006, 'Nutrition of the critically ill patient and effects of implementing a nutritional support algorithm in ICU', Journal of Clinical Nursing 15(2), 168-177. https://doi.org/10.1111/j.1365-2702.2006.01262.x 